\title{
Serological diagnosis of infectious mononucleosis using three anti-Epstein-Barr virus recombinant ELISAs
}

\author{
Inge Färber ${ }^{a}$, Peter Wutzler ${ }^{a}$, Peter Wohlrabe ${ }^{a}$, Hans Wolf ${ }^{b}$, \\ Walter Hinderer ${ }^{c}$ and Hans-Hermann Sonneborn ${ }^{c}$ \\ ${ }^{a}$ Institute of Medical Microbiology, Medical Academy, Erfurt (FRG), ${ }^{b}$ Institute of Medical \\ Microbiology, University of Regensburg, Regensburg (FRG) and \\ ${ }^{2}$ Research Department, Biotest AG, Dreieich (FRG)
}

(Accepted 30 November 1992)

\section{Summary}

A new Epstein-Barr virus (EBV) ELISA system (Biotest Anti-EBV recombinant) was evaluated for usefulness for routine diagnosis of EBV primary infection. The assay system is composed of three different microtest plates coated with three highly purified recombinant EBV antigens. The early antigens p138 (BALF2, truncated) and p54 (BMRF1, whole sequence) are used as a mixture for testing IgM (assay 1 ) and IgG (assay 2) antibodies. In addition, the EBNA-1 antigen p72 (BKRF1, carboxy-half) is used for detecting IgG antibodics (assay 3 ).

Three panels of sera were examined in direct comparison with standard immunofluorescence (IF): Specimens of (i) 120 infectious mononucleosis (IM) patients, (ii) 60 patients with acute CMV infection, toxoplasmosis or rheumatic disease, respectively, and (iii) 185 healthy blood donors as a control group.

119 IM patients were clearly recognized as having acute primary infection (sensitivity $99.2 \%$ compared to VCA-IgM by IF). Three apparently falsepositive results were obtained with patients of other diseases and none within the control group (specificity 98.8\%). The data suggest that the recombinant ELISA can be used advantageously for standardized rapid diagnosis of acute EBV primary infection.

Infectious mononucleosis; Serological diagnosis; Epstein-Barr virus; ELISA system

Correspondence to: I. Färber, Institute of Medical Microbiology, Medical Academy Nordhäuser Str. 74, 0-5010 Erfurt, FRG. 


\section{Introduction}

Many years before the Epstein-Barr virus (EBV) was discovered serodiagnosis of infectious mononucleosis (IM) was based on the Paul-Bunnell test for heterophile antibodies (Paul and Bunnell, 1932). Testing for heterophile antibodies is still widespread in routine diagnosis. However, despite the relatively high degree of specificity of the Paul-Bunnell agglutinins for the early stage of IM the test fails in some cases particularly with young children (Evans et al., 1975, Schmitz et al., 1972). Therefore, serodiagnosis of IM by measuring the specific antibody response is clearly to be preferred.

Primary EBV infections whether or not accompanied by clinical signs of IM lead to the appearance of antibodies to various EBV-specific antigens which are usually detected by immunofluorescence (IF) staining of EBV infected cells (Henle et al., 1974). The typical antibody pattern of primary EBV infection is characterized by IgM and IgG antibodies to virus capsid antigen (VCA), IgG antibodies to early antigens (EA) and the absence of antibodies to nuclear antigens (EBNA).

For routine purposes, immunofluorescence assays are time consuming, difficult to evaluate, and cannot be exactly standardized. Moreover, the evaluation of EBV-specific immunofluorescence may be considerably hampered by autoantibodies to various cellular antigens which emerge in the course of IM in most patients (Sutton et al., 1974).

These problems might be solved by utilizing highly purified recombinant EBV polypeptides as antigens (Motz et al., 1986; Wolf et al., 1985). Several putative test-antigens have been evaluated extensively recently. (Hinderer et al., 1988, Gorgievski-Hrisoho et al., 1990). Three were used to develop a new generation of EBV-ELISA ('Biotest Anti-EBV recombinant') for detecting IgG and IgM antibodies to EA (p138 and p54) and IgG antibodies to EBNA (p72).

The present study was designed to evaluate the usefulness of this new ELISA system for routine diagnosis of primary EBV infections. Well-defined cases of IM diagnosed by heterophile antibodies and EBV-specific standard immunofluorescence were investigated in comparison with two control groups, i.e. healthy blood donors and patients with other infectious or rheumatic diseases.

\section{Material and Methods}

\section{Clinical specimens}

Sera were collected from 100 patients with heterophile positive IM (aged 4 $29 \mathrm{yr}$, mean $12.9 \mathrm{yr}$ ) and 20 patients with heterophile negative IM (aged 2-12 $\mathrm{yr}$, mean $5,1 \mathrm{yr}$ ). All cases were confirmed by positive VCA-IgM results $(>1: 10)$ using IF and a negative or weakly positive anti-EBNA result by means of anticomplement immunofluorescence (ACIF). Controls were 185 healthy blood donors. Another control group consisted of 60 patients with other 
TABLE 1

Recombinant EBV antigens

\begin{tabular}{llll}
\hline Protein & $\mathrm{p} 54$ & $\mathrm{p} 138$ & $\mathrm{p} 72$ \\
\hline $\begin{array}{l}\text { Reading frame } \\
\text { Classification }\end{array}$ & $\begin{array}{l}\text { BMRF 1 } \\
\text { Early antigen (EA-D) }\end{array}$ & $\begin{array}{l}\text { BALF 2 } \\
\text { Early antigen ('major } \\
\text { DNA-binding protein') } \\
\text { Fusion of two } \\
\text { selected sections }\end{array}$ & $\begin{array}{l}\text { BKRF 1 } \\
\text { Nuclear antigen } \\
\text { (EBNA-1) } \\
\text { C-terminal part (46.2\%) }\end{array}$ \\
$\begin{array}{l}\text { Construction } \\
\begin{array}{l}\text { Size of expressed } \\
\text { protein }\left(M_{\mathrm{r}}\right)\end{array}\end{array}$ & $52 / 47 \mathrm{kDa}$ & $46 \mathrm{kDa}$ \\
$\begin{array}{l}\text { Concentration in } \\
\text { Coating solution }\end{array}$ & $0.875 \mu \mathrm{g} / \mathrm{ml}$ & $0.875 \mu \mathrm{g} / \mathrm{ml}$ & $0.125 \mu \mathrm{g} / \mathrm{ml}$ \\
\hline
\end{tabular}

infections (acute cytomegalovirus infection, $n=20$; toxoplasmosis, $n=20$ ) or rheumatic diseases $(n=20)$.

Recombinant EBV antigens and ELISA procedure

The assay system is composed of different microplate ELISAs for detecting IgM and IgG antibodies to highly purified recombinant EBV antigens immobilized onto the solid phase. The early antigens p138 (BALF2, truncated) and p54 (BMRF1, whole sequence) are coated as a mixture for testing IgM and IgG antibodies. The EBNA-1 antigen p72 (BKRF1, carboxyhalf) is used for detecting IgG antibodies.

The construction of the clones and the concentrations in coating solutions are shown in Table 1. The configuration of the ELISA is given in Table 2.

Sera were diluted $1: 21$ and incubated with the immobilized antigens (microtest plates, 96 wells) at $40^{\circ} \mathrm{C}$ for either $30(\mathrm{IgG})$ or $60(\mathrm{IgM}) \mathrm{min}$. After washing steps the second antibody was incubated at $40^{\circ} \mathrm{C}$ for $30 \mathrm{~min}$ followed by further washing procedures. The reaction with substrate (1,2-phenylenediamine) was performed at room temperature for $15 \mathrm{~min}$. All volumes were $100 \mu \mathrm{l}$. The absorption values were measured at $492 / 620 \mathrm{~nm}$. Blank, negative and positive controls were included on each plate. The cut-off values were defined as optical density (O.D.) of the negative control +0.15 .

Standard laboratory diagnosis

EBV-specific antibodies to VCA (IgG and IgM) and EA (IgG) were determined by indirect immunofluorescence (IF) on the basis of slides prepared from antigen producing P3HR-1 (VCA) and chemically induced Raji cells (EA $\mathrm{R}+\mathrm{D}$ ) (Henle et al., 1974). To avoid nonspecific $\operatorname{IgM}$ reactivities due to the presence of rheumatoid factors and antigen-specific IgG the sera were preabsorbed by anti-IgG (RF-Absorbent, Behringwerke AG, FRG).

Antibodies against EBNA were detected by ACIF on slides prepared from nonproducing Raji cells (Reedman and Klein, 1973). 
Testing for heterophile antibodies was carried out by a modified PaulBunnell assay (Wöllner, 1962). Sera with a titer $\geqslant 1: 12$ were considered positive.

\section{Results}

The distribution of reactivities for each ELISA within the 3 panels of sera is shown in Table 2. Of the $120 \mathrm{IM}$ sera tested all but one were positive by the IgM-ELISA, mostly $(64.2 \%)$ with values of $>1.000$ O.D. By contrast, $96.2 \%$ of the healthy blood donors and $65.0 \%$ of the patients with cytomegalovirus infection, toxoplasmosis or rheumatic diseases were negative with this assay.

The IgG ELISA yielded positive results with all samples from IM, half of which had very high absorption values (O.D. $>2.000$ ). The positive rate of blood donors was only $9.7 \%$. However, $56.7 \%$ of patients with other diseases displayed EA-IgG reactivities.

The EBNA-IgG ELISA showed a reverse situation. Among the IM sera $92.5 \%$ were clearly negative for EBNA-IgG whereas $78.9 \%$ of the controls reacted with this antigen, mostly with high O.D. values $(>1.000)$.

Concerning the results of three anti-EBV ELISA markers each patient was placed in a diagnostic scheme which covers the various stages of EBV infection (Table 3). The pattern indicative of primary infection (EA-IgM and -IgG positive; EBNA-IgG negative or at most weakly positive) were obtained with 119 out of $120 \mathrm{IM}$ cases. The remaining patient displayed an intermediate pattern between acute and past-infection. Therefore, the overall sensitivity of the ELISA system was $99.2 \%$.

None of the healthy blood donors had a pattern for primary infection. Within this group the specificity was $100 \%$. In contrast, four samples had a pattern of primary infection within the panels of other diseases. Additional IF assays with these sera confirmed one of these four patients as primary EBV

TABLE 2

Distribution of reactivities of the three recombinant ELISAs

\begin{tabular}{|c|c|c|c|c|c|c|c|c|c|}
\hline \multirow{2}{*}{$\begin{array}{l}\text { Range of } \\
\text { OD values }\end{array}$} & \multicolumn{3}{|c|}{ IgM-ELISA (p54 + pl38) } & \multicolumn{3}{|c|}{ IgG-ELISA (p54 + p138) } & \multicolumn{3}{|c|}{ EBNA-ELISA (p72) } \\
\hline & $\mathrm{IM}$ & $\begin{array}{l}\text { Other } \\
\text { dis. }(\%)\end{array}$ & $\begin{array}{l}\text { Blood } \\
\text { donors }\end{array}$ & IM & $\begin{array}{l}\text { Other } \\
\text { dis. }(\%)\end{array}$ & $\begin{array}{l}\text { Blood } \\
\text { donors }\end{array}$ & IM & $\begin{array}{l}\text { Other } \\
\text { dis. }(\%)\end{array}$ & $\begin{array}{l}\text { Blood } \\
\text { donors }\end{array}$ \\
\hline $0<$ cut-off & 0.8 & 65.0 & 96.2 & 0 & 43.3 & 91.3 & 85.0 & 25.0 & 21.1 \\
\hline cut-off- -0.500 & 18.3 & 20.0 & 1.6 & 10.0 & 33.3 & 2.2 & 15.0 & 10.0 & 7.6 \\
\hline $0.501-1.000$ & 16.7 & 10.0 & 1.6 & 17.5 & 13.3 & 1.6 & 0 & 5.0 & 10.8 \\
\hline $1.001-2.000$ & 31.7 & 3.3 & 0.6 & 21.7 & 6.7 & 1.1 & 0 & 10.0 & 119 \\
\hline$>2.000$ & 32.5 & 1.7 & 0 & 50.8 & 3.3 & 1.8 & 0 & 50.0 & 48.6 \\
\hline
\end{tabular}

Comparison of acute IM sera $(n=120)$ with control groups of patients with other infectious or rheumatic diseases $(n=60)$ and healthy blood donors $(n=185)$.

$\mathrm{IM}=$ infectious mononucleosis, other diseases: cytomegalovirus infections $(n=20)$, toxoplasmosis $(n=20)$, rheumatic diseases $(n=20)$. 


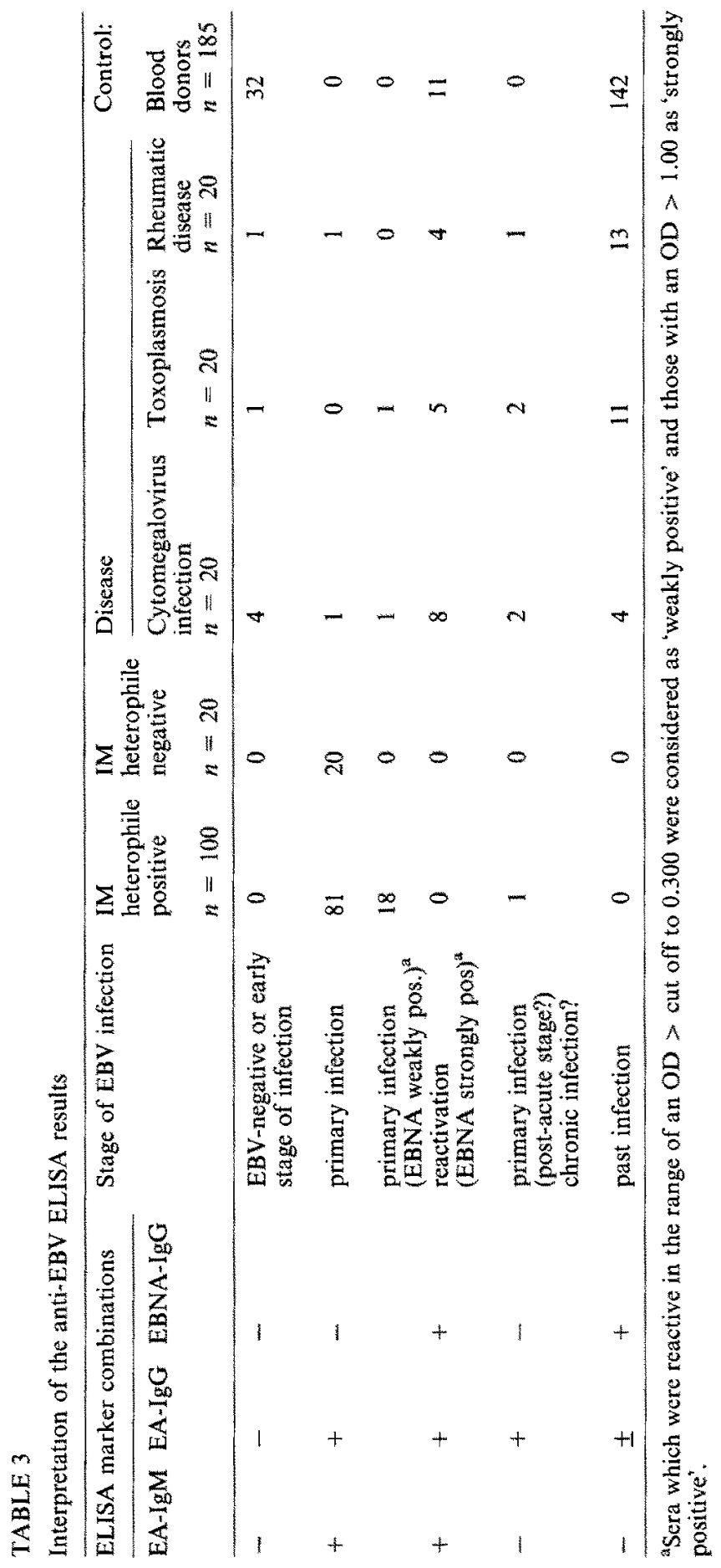


infection, two as possible reactivations and one patient could not be diagnosed by reason of anti-cellular antibodies. The overall specificity was at least $98.8 \%$, i.e. three out of 245 were apparently false-positives. A small portion of the healthy control group $(6 \%)$ and a more significant portion of the disease control group $(28 \%)$ exhibited a reactivity pattern indicative of EBV reactivation.

\section{Discussion}

EBV-specific tests for infectious mononucleosis are usually based on the presence of IgM antibodies to VCA and the absence of anti-EBNA antibodies. Anti-EA-IgG antibodies when detected by IF using induced EBV infected cells are present during acute IM in only two-thirds of the cases (Henle et al., 1971). However, when the antibody response to individual viral polypeptides was determined by immunoblot, IgG and IgM reactivity to the EA polypeptides p138 and p45-52 was detectable in the first serum samples of all acutely infected IM patients (Middeldorp and Herbrink, 1988). Recently, Gorgievski-Hrisoho et al. (1990) tested several recombinant EBV antigens, selected by Wolf et al. (1985) and Motz et al. (1986), with respect to reactivity among well-defined IM sera. It was shown, that particularly the EA proteins p138 and p54 were excellently recognized by sera from patients with acute IM. On this basis, and including the EBNA-1 protein p72 as the third marker, the novel recombinant ELISA was established.

Our results from acute IM demonstrate the usefulness of these assays in routine diagnosis of acute primary EBV infection when compared with the standard IF technique as a gold standard. The marked differences in the reactivities with the three ELISAs between IM and control groups underline the high diagnostic potential of the assay system. Among the 100 cases of heterophile positive IM and the 20 cases of heterophile negative IM only one was not recognized as having acute primary EBV infection (sensitivity $99.2 \%$ ). On the other hand, three apparently false-positive results were obtained with patients of other diseases and none within the control group of blood donors (specificity $98.8 \%$ ).

For the ELISAs a general pretreatment of serum specimens with rheumatoid factor (RF) absorbent was not incorporated since false-positive IgM results caused by RF are only to be expected in sera which are highly reactive for EAIgG. However, high reactivity with the EA-IgG ELISA in combination with a negative or weakly positive EBNA-ELISA is a marker for acute primary EBV infection independently from the IgM reactivity. Pretreatment of serum specimen to absorb IgG should be performed when the marker constellation EBNA-IgG positive, EA-IgM weakly positive and EA-IgG strongly positive was obtained.

In conclusion, the data indicate that the recombinant ELISA system yields not only results which are comparable with the standard IF methods but also 
offers advantages, e.g. simple and rapid performance, objective reading of results, reduced interference with rheumatoid factor, however no interference with anti-cellular antibodies.

\section{References}

Evans, A.S., Niederman, J.C., Cenabre, L.C., West, B. and Richards, V.A. (1975) A prospective evaluation of heterophile and Epstein-Barr virus-specific IgM antibody tests in clınical and subclinical infectious mononucleosis. J. Infect. Dis. 132, 546-554.

Gorgievski-Hrisoho, M., Hınderer, W., Nebel-Schickel, H., Horn, J., Vornhagen, R., Sonneborn, H.-H., Wolf, H. and Siegl, G. (1990) Serodiagnosis of infectious mononucleosis by using recombinant Epstein-Barr virus antigens and enzyme-linked 1mmunosorbent assay technology. J. Clin. Microbiol. 28, 2305-2311.

Henle, W., Henle, G., Niederman, J.C., Klemola, E. and Haltia, K. (1971) Antibodies to early antigens induced by Epstein-Barr virus in infectious mononucleosis. J. Infect. Dis. 124, 58-67.

Henle, W., Henle, G. and Horwit7. C.A. (1974) Epstein-Barr virus specific diagnostic tests in infectious mononucleosis. Hum. Pathol. 5, 551-565.

Hinderer, W., Nebel-Schickel, H., Sonneborn. H.-H., Motz, M., Kühbeck, R. and Wolf, H. (1988) Purification of four different recombinant EBV-antigens synthesized in $E$. coli and their diagnostic application. J. Exp. Clin. Cancer Res. 7 (Suppl.) 132.

Middeldorp, J.M. and Herbrınk, P. (1988) Epstein-Barr virus specific marker molecules for early diagnosis of infectious mononucleosis. J. Virol. Methods 21, 133-146.

Motz, M., Fan, J., Seibl, R., Jilg, W. and Wolf, H. (1986) Expression of the Epstein-Barr virus 138kDa early protein in Escherichia coli for the use as antigen in diagnostic tests. Gene 42, 303-312.

Paul, J.R. and Bunnell, W.W. (1932) The presence of heterophle antibodies in infectious mononucleosis. Am. J. Med. Sci. 183, 91-104.

Reedman, B.M. and Klein, G. (1973) Cellular localization of an Epstein-Barr virus (EBV)associated complement-fixing antigen in producer and nonproducer lymphoblastoid cell lines. Int. J. Cancer 11, 499-520.

Schmitz, H., Volz, D., Krainick-Riechert, C. and Scherer, M. (1972) Acute Epstein-Barr virus infections in children. Med. Microbiol. Immunol. 158, 58-63.

Sutton, R.N.P., Edmond, R.T.D., Thomas, D.B. and Doniach, D. (1974) The occurrence of autoantibodies in infectious mononucleosis. Clin. Fxp. Immunol 17, 427-436.

Wolf, H., Motz, M., Kühbeck, R., Seibl, R., Bayliss, G.J., Modrow, S. and Fan, J. (1985) Selection and production by genetechnological methods of medically relevant EBV-related antigens. In: P.H. Levine, D.V. Ablashı and G.R. Pearson (eds.), Developments in medical virology, vol. 1, Epstein-Barr virus and associated diseases. M. Nijhoff Publ.. Boston, pp. 485-494.

Wöllner, D. (1962) Neue Methoden zur serologischen Diagnostık der infektiösen Mononukleose. Dtsch. Med. Wschr. 87, 1504-1506. 